\title{
Parkinsonism in Ontario: Physician Utilization
}

\author{
M. Guttman, P.M. Slaughter, M-E. Theriault, D.P. DeBoer, C.D. Naylor
}

\begin{abstract}
Background: Patients with Parkinsonism have a progressive disorder requiring substantial expertise to manage effectively. Methods: Over a six-year period we evaluated physician utilization and related costs for a large, unselected cohort of 15,304 Parkinsonian patients from the general population, comparing them to 30,608 age- and sex-matched controls within a universal health care system in Ontario, Canada. Results: On average, $45 \%$ of Parkinsonian patients saw neurologists annually. The cumulative rate of at least one neurological consultation was only $59.5 \%$ over the six years. Patients aged $<65$ had a much greater likelihood of consulting a neurologist $(73.3 \%)$ compared to those $\geq 65(37.2 \%)$. Most Parkinsonian patients (97.2\%), regardless of age, saw family physicians/ general practitioners each year; $50.4 \%$ saw internal medicine consultants. Conclusions: Parkinsonian patients had increased likelihood of utilizing neurologists, primary care physicians and internists compared to controls; related costs of physicians' services were higher. Further research is necessary to evaluate differences in outcomes and costs between neurologists and other physician service providers.
\end{abstract}

RÉSUMÉ: Le parkinsonisme en Ontario: utilisation des soins prodigués par le médecin. Introduction: Les patients parkinsoniens ont une maladie progressive dont la prise en charge efficace requiert une expertise substantielle. Méthodes: Nous avons évalué le recours aux soins prodigués par un médecin et les coûts afférents chez une cohorte de 15304 patients parkinsoniens de la population en général sur une période de six ans et nous les avons comparés à ceux d'un groupe de 30608 contrôles appariés pour l'âge et le sexe, tirés du système universel de soins de santé de l'Ontario, au Canada. Résultats: En moyenne, 45\% des parkinsoniens ont vu un neurologue de façon annuelle. Le taux cumulatif d'au moins une consultation neurologique était seulement de 59,5\% sur six ans. Les patients de moins de 65 ans étaient plus susceptibles d'avoir consulté un neurologue $(73,3 \%)$ par rapport à ceux de plus de 65 ans (37,2\%). La plupart des parkinsoniens (97,2\%), sans égard à l'âge, consultaient un médecin de famille/médecin généraliste à chaque année; $50,4 \%$ voyaient un interniste. Conclusions: Les parkinsoniens avaient une plus grande probabilité d'utiliser les services d'un neurologue, d'un médecin de première ligne et d'un interniste que les contrôles; les coûts afférents aux services de médecins étaient plus élevés. L'évaluation de différences dans les résultats et les coûts des soins prodigués par les neurologues et les autres médecins nécessite des recherches plus poussées.

Can. J. Neurol. Sci. 2002; 29: 221-226

Current therapeutic strategies for Parkinson's disease (PD) offer symptomatic improvement, ${ }^{1}$ but the mortality associated with Parkinsonism continues to be more than double that of an age- and sex-matched control group. ${ }^{2}$ Parkinsonian patients have an increased rate of hospitalization and have higher health costs relating to physician visits and drug utilization compared to controls. Costs of PD are expected to grow globally with the population aging and the epidemiological transition to chronic diseases late in the life course.

The management of PD patients is often complex and, as the disease progresses, requires extensive expertise to optimize the available strategies. ${ }^{3,4}$ Neurologists are specifically trained to deal with PD but internal medicine specialists and primary care physicians (including family physicians and general practitioners) also provide care to PD patients and may lack the training and expertise to provide optimal care. Decisions relating to health care access and drug utilization are determined largely by the physicians who manage PD patients, yet there are, to our knowledge, no reports in the health services research literature describing the types of physicians providing services to PD patients in the general population.

From the Division of Neurology, Department of Medicine, University of Toronto, (MG), Institute for Clinical Evaluative Sciences (PMS, M-ET, DPD, CDN), Dean's Office, Faculty of Medicine, University of Toronto (CDN) Toronto, Ontario ReCEIVEd November 28, 2001. ACCEPTED IN FinAL FORM February 25, 2002 Reprint requests to: Mark Guttman, 377 Church St. \#407, Markham, Ontario, Canada, L6B 1A1 
In the universal Canadian health care system, family physicians and general practitioners provide services directly to patients without a referral. Specialty care, including access to internists and neurologists, is available without any limitations as long as a physician requests a referral.

The objective of the study was to use large, linked administrative databases to assess which physicians provide services to Parkinsonian patients in a setting of a geographicallydelimited population. We performed this study in Ontario, which is the most populous province with a population of approximately eleven million (or 38\% of the total population of Canada). Over a six-year period we prospectively evaluated the distribution and costs of physician services provided to a large, unselected cohort of Parkinsonian patients from the general population - identified by physician diagnosis and drug utilization - and compared them to age- and sex-matched controls within a universal health care system.

\section{MethodS}

A detailed description of the methodology used for this study has been published. ${ }^{2}$ Briefly, the Ontario Health Insurance Plan (OHIP) claims database, the Ontario Drug Benefit (ODB) Program claims and the Registered Persons Database (RPDB) were linked. This unique linked data set allows the examination of demographic information, claims for physician visits, prescription drug utilization, and hospitalization experience at the individual patient level. Ontario Health Insurance Plan claims data include the primary diagnosis made by the attending/consulting physician in relation to the service provided. Ontario Drug Benefit data include claims submitted by pharmacists to the government's drug benefit program for outpatient prescription drugs provided to persons 65 years of age and over. The RPDB contains health card number, sex, date of birth, postal code and death date (where applicable) associated with the carrier of each valid Ontario health card.

Patients were identified by the use of the International Classification of Diseases - 9th revision (ICD-9) diagnostic code for PD or other forms of Parkinsonism (332) in the OHIP database; by the use of specific PD drugs in the ODB database; or, a combination of both. These drugs included in the analysis, in both brand name and generic formulations as applicable: levodopa, levodopa/carbidopa (brand name, generic and controlled release), levodopa/benzeraside combinations, selegiline (brand name and generic), bromocriptine (brand name and generic), pergolide, tolcapone, ropinirole, pramipexole and amantadine. Patients who were treated solely with amantadine during the influenza season (between November and April) were excluded. As the drug benefit database does not include patients under age 65 , bromocriptine therapy for women for post-partum lactation suppression was not an issue. Patients were included if they were over the age of 25 , on the assumption that a diagnosis of Parkinsonism under this age represented a coding error. We identified an inception cohort for fiscal year (1993/94). ${ }^{2}$ The cohort was followed longitudinally for six years (1993/94 1998/99). Parkinsonian cases meeting the restrictions of cohort inclusion were matched by age in years and sex with two controls without Parkinsonism from the general population of the RPDB (1:2 ratio). Multiple counting did not occur since the dataset compilation utilized a unique scrambled numeric code for each patient included.

We identified types of physicians who were most likely to take an active role in the treatment of parkinsonism. These study physicians included general/family physicians and internal medicine specialists. Other types of physicians were considered to be nonstudy physicians. ${ }^{2}$

The Parkinsonian and control cohorts were assessed annually to evaluate the number of patients who had at least one physician service claim for neurologists, family/general physicians and internists. An odds ratio was calculated to determine the likelihood of the Parkinsonian case and control groups seeing that type of physician. The average cost for physician services per year was calculated per person year survival (PYS) for both cohorts. The Parkinsonian case cohort was divided into two groups: those who had seen a neurologist were separated from those who did not to evaluate the proportion of patients seeing the other types of study physicians each year.

The analyses were performed on a Sun Sparc Enterprise 3000 running Solaris 2.6 (Unix) using SAS (version 6.12, SAS Institute, Inc., Cary, NC).

\section{Error Estimation for Under 65 Population}

We attempted to estimate potential errors that may have occurred in the compilation of the (Parkinsonian cases and controls) database. Since we did not have drug utilization data in the under 65 population, we attempted to estimate the number of patients with Parkinsonism that may have been missed utilizing the patterns observed in the over 65 age group. The percent of those over 65 identified only by ODB will be used as a marker of the error.

The three groups of study physicians (neurologists, internists and family/general practitioners) were compared to assess the number of patients in the over 65 population identified with OHIP claims diagnostic codes versus the use of ODB data. Using this methodology, patients identified only in the OHIP database should represent patients with Parkinsonism who are not taking medication for Parkinsonism, or are taking medication paid for by means other than ODB (other private insurance plans or self payment). Patients identified with both OHIP and ODB should represent the majority of patients, anticipating that the bulk of the patient population receive drug benefits provided by ODB.

Assuming appropriate utilization of Parkinsonian drugs based on this methodology, patients identified in the ODB-only group represent a patient population that:

1. was being seen by that physician for another diagnostic problem;

2. was not coded properly for their Parkinsonian diagnostic code; or

3. had the diagnosis of Parkinsonism by another physician type.

\section{RESULTS}

The two cohorts included 15,304 Parkinsonian patients and 30,608 controls. The percentage error for the under 65 population due to lack of ODB information is estimated as $4.71 \%$ of the total cohort. We conclude that the unadjusted cohort is therefore over $95 \%$ accurate in estimating the patient population based on the methods employed. 


\section{Study Physician Services and Costs}

The proportion of Parkinsonian cases seeing neurologists and other types of physicians is found in Figure 1. Averaged over the period of the study, $45 \%$ of Parkinsonian cases saw a neurologist at least once annually (Table 1a). The cumulative percentage of Parkinsonian cases who saw a neurologist on at least one occasion over the six years of the study was only $59.5 \%$ of the cohort. There was a difference in the proportion of Parkinsonian cases who saw a neurologist each year based on their age at the time of the inception of the cohort (Figure 2). Parkinsonian cases below the age of 65 saw neurologists more frequently (on average $73.3 \%$ each year) compared to those age 65 or older (on average $37.2 \%$ each year). The vast majority of Parkinsonian patients saw family physicians (on average $97.2 \%$ each year); a smaller proportion saw internal medicine specialists $(50.4 \%$ each year).

Parkinsonian cases saw all of the study physicians more frequently than controls (Table 1a, 1b, 1c). Over the study period the odds ratio of seeing a neurologist for Parkinsonian cases compared to controls ranged between 15.5-19.7 (Table 1a). The odds ratio of seeing a family/general physician for a Parkinsonian case compared to control ranged between 3.2 and 13.1 (Table 1b). There was a slightly higher proportion of cohort Parkinsonian cases visiting internal medicine specialists compared to cohort controls with an odds ratio that ranged from 1.1 to 1.4 (Table $1 \mathrm{c}$ ).

The Parkinsonian cases were classified into two separate categories - having seen a neurologist or not having seen a neurologist that year - to examine the proportion of patients consulting different physician types on an annual basis. Of the Parkinsonian patients who did not see a neurologist, only $40.1 \%$ saw internal medicine specialists and $7.6 \%$ were not evaluated by any study physicians.

The physician claims cost (OHIP) for neurological care per PYS was 9.6 times higher for Parkinsonian cases ( $\$ 78.90$ versus \$8.37) than for controls (Figure 3a, 3b). The average annual consultative cost for family/general physicians was 1.6 times more per PYS in the Parkinsonian group compared to cohort controls (\$436.01 versus \$279.70). The average annual consultative costs for internists per PYS were 1.1 times higher for cohort Parkinsonian cases as compared to controls $(\$ 168.70$ versus \$154.85).

For the Parkinsonian cases group, the average annual percentage of total OHIP costs for neurologists was $7 \%$; for family/general physicians was $40 \%$; for internal medicine specialists was $15 \%$; and for nonstudy physicians was $38 \%$. For the control group, the average annual percentage of total cohort OHIP costs for neurologists was $1 \%$; for family/general physicians was $36 \%$; for internal medicine specialists was $20 \%$; and for nonstudy physicians was $43 \%$.

\section{DISCUSSION}

To our knowledge, this is the first study to assess which types of physicians are providing care to patients with Parkinsonism. We observed a lower-than-expected rate of neurological consultation in our Parkinsonian patient population. The accumulative rate of at least one neurological consultation in our cohort of cases with Parkinsonism was only $59.5 \%$ over the six years. When each year was examined, the average annual rate was only $45 \%$. Patients under age 65 had a much greater likelihood of consulting a neurologist (73.3\% annual average) as compared to those 65 and over (37.2\% annual average). We did not observe an increase in access to neurologists as the duration of Parkinsonism extended and expected severity increased, when patients might understandably require more complex care. The general population showed no change in the frequency of neurological consultations over the six-year period. Thus, one would not expect an increase or decrease in neurological access arising from aging of the cohort alone. All patients had access to a universal health care system at no direct cost to themselves; therefore both the Parkinsonian patient and control populations should have received an equally high level of health care services.

The methodology used may have created a bias in determining the cohort Parkinsonian case group under the age of 65. As stated in the section entitled "Error Estimation for $<65$ Population" (see Methods), we may have underestimated our cohort since the OHIP claims database was the only one utilized to determine this population. We estimated this error, however, to be less than $5 \%$ of our Parkinsonian cohort. For that reason we may have underestimated the referral rate to physicians and their related costs. Similarly, we may have over-estimated the annual percentage of patients seeing neurologists for the under age 65 group. Since we have estimated that the potential error is small, it is unlikely that this would substantially alter our conclusions.

However, if our data are correct, a significant proportion of the Parkinsonian patient population may not be getting optimal medical care by the appropriate specialists. Furthermore, there appears to be an access bias in the population age 65 years of age and over, which suggests that these patients have a significantly reduced access to specialized services than younger patients under 65. It is unclear why more patients with parkinsonism do not have access to neurological care. It is possible that patients under age 65 are more aggressive in seeking specialty care; that there may be an access problem to neurologists by the elderly; or that there is some type of referral bias that reduces the rate of neurological consultations and follow-up in the elderly. This low overall rate of neurologist utilization is an unexpected finding and may be due to a number of factors, including undersupply of neurologists, geographic issues or referral patterns of primary care physicians. This is clearly an area for future study.

In Canada, general practitioners or family physicians provide primary care; internal medicine specialists and neurologists, provide consultation services. Physicians do not have a financial or other disincentive for referral of patients to specialists. Annually, the primary care physicians saw on average $97.2 \%$ of patients; internal medicine specialists saw on average $50.4 \%$ of patients each year over the six years of the study. Of the Parkinsonian patients who did not see a neurologist, only $40.1 \%$ saw internal medicine specialists, suggesting that $31.5 \%$ of the total Parkinsonian cohort were never referred to a specialist, or that one was not available in that area. It is quite possible that referrals to internal medicine specialists were for completely unrelated health problems and that the proportion of patients not receiving specialist care for Parkinsonism may be much higher.

More Parkinsonian cases (odds ratio 15.5-19.7) saw neurologists than did controls, and the annual cost per PYS of seeing a neurologist was on average 9.4 times higher. 


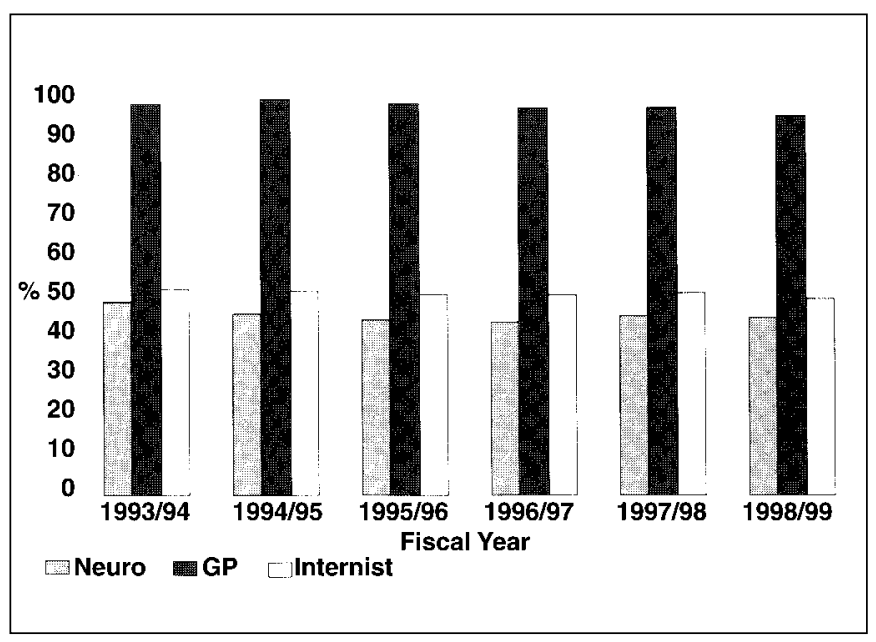

Figure 1: Average annual percentage of PD cases seen by neurologists, internists and primary care MDs per person years of survival (PYS) in Ontario by fiscal year 1993/94-1998/99.

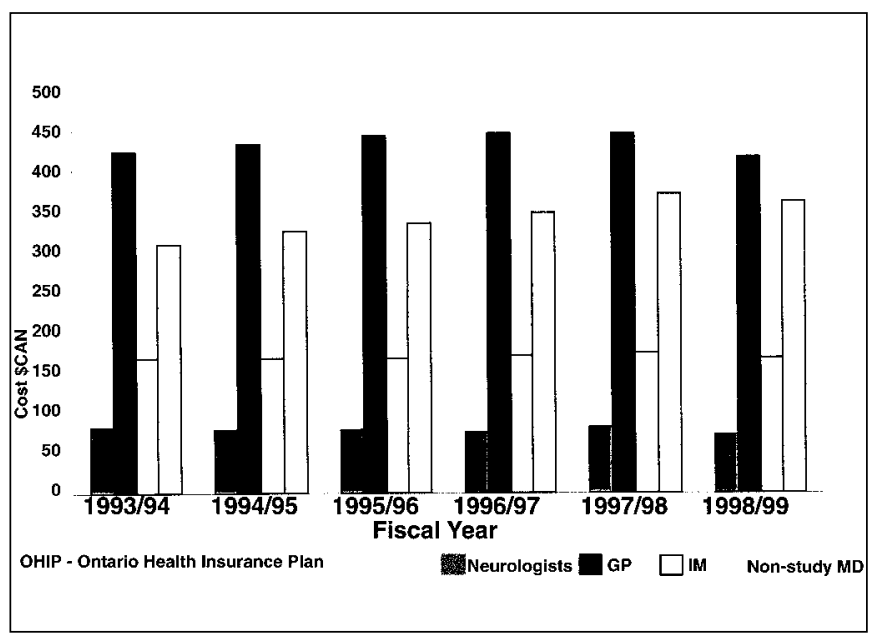

Figure 3a: Average annual OHIP cost (\$CAN) per person years survival (PYS) for cohort Parkinsonian cases in Ontario by fiscal year 1993/94-1998/99.

Parkinsonian cases saw primary care physicians more frequently than controls (odds ratio 3.2-13.1) at a 1.56 times higher annual cost. Parkinsonian cases saw internists slightly more often (odds ratio 1.2-1.4) than controls, but the cost of internal medicine services was essentially the same for both groups (only 1.1 times more than controls). Parkinsonian cases were compared to ageand sex-matched controls to examine differences in access to medical care. It is possible that geographic location had an impact on the observed differences in access to physicians between the two groups. Since we did not perform matching based on location, we are unable to assess if the differences were in part due to geographic differences of the Parkinsonian cases and controls. The proportion of physician costs for neurological

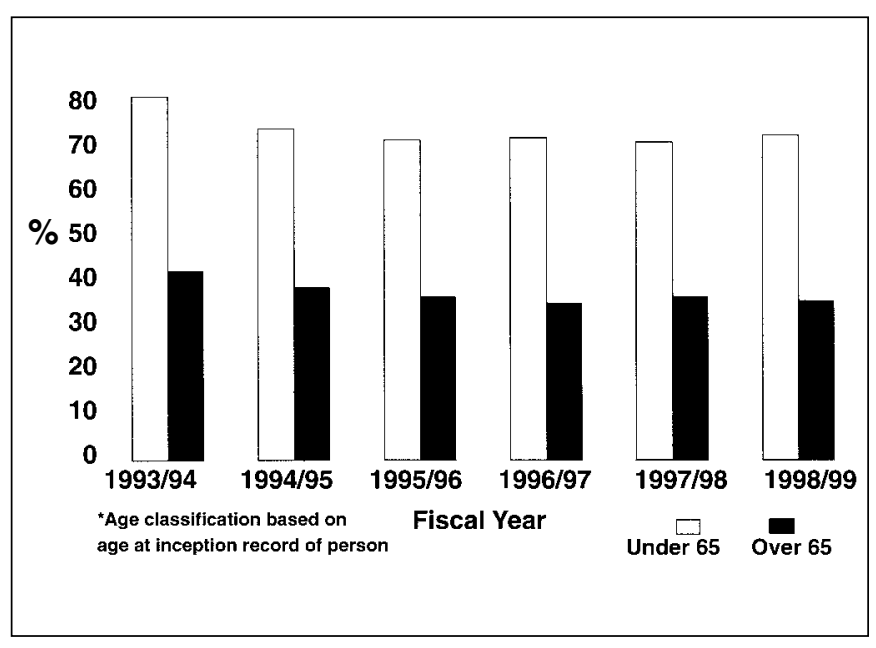

Figure 2: Percentage of cohort PD patients seen by neurologists by age* groupings $>65$ and $\leq 65$ in Ontario by fiscal year 1993/94-1998/99.

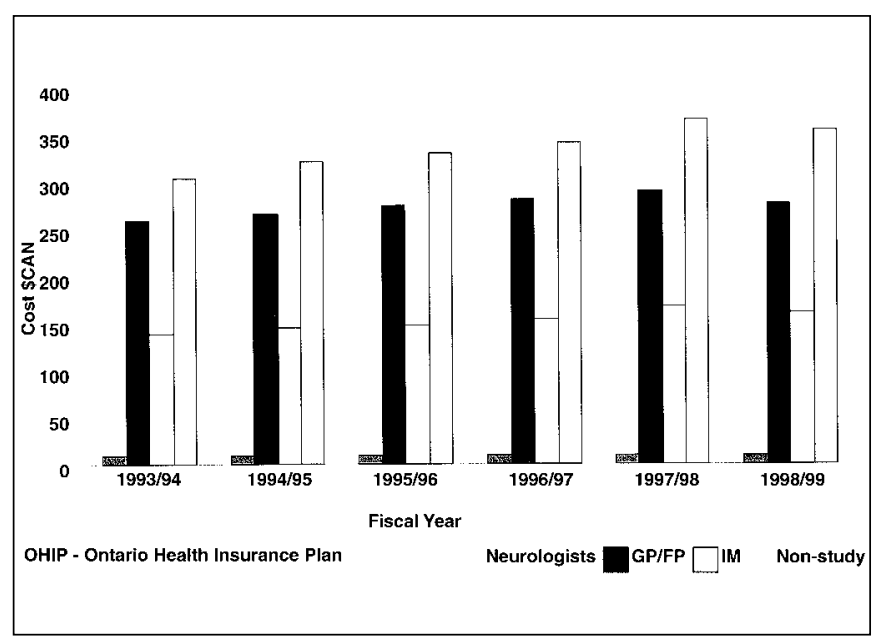

Figure 3b: Average annual OHIP cost (\$CAN) per person years survival (PYS) for cohort controls in Ontario by fiscal year 1993/94$1998 / 99$.

services was only $7 \%$ for the Parkinsonian cohort, with the majority of resources spent on services provided by other physicians. We are not aware of prior studies that evaluated costs of health care compared to age- and sex-matched controls.

Parkinsonian cases identified were derived from a crosssection of the Parkinsonian population. It was not possible to identify the clinical severity of disease in the cases with Parkinsonism nor the duration of disease from the administrative database. However, given the population-based nature of the study, the patients included should be fully representative of the general population of patients with the disease.

We believe it unlikely that our observations in this study are due to some methodological error. ${ }^{2}$ We are unable to identify if 
Table 1a: Numbers and odds ratios of Parkinsonian cases and controls seeing neurologists at least once in Ontario by fiscal year 1993/94-1998/99

\begin{tabular}{llllll}
\hline & \multicolumn{2}{c}{ Parkinsonian Cases $(\mathbf{n = 1 5 , 3 0 4 )}$} & \multicolumn{3}{c}{ Controls (n=30,608) } \\
Fiscal Year & $\begin{array}{l}\text { Number Seen by } \\
\text { Neurologist }\end{array}$ & $\begin{array}{l}\text { \% Seeing } \\
\text { Neurologist }\end{array}$ & $\begin{array}{l}\text { Number Seen by } \\
\text { Neurologist }\end{array}$ & $\begin{array}{l}\text { \% Seeing } \\
\text { Neurologist }\end{array}$ & $\begin{array}{l}\text { Neurologist Odds } \\
\text { Ratio (95\% CI) }\end{array}$ \\
\hline \multirow{2}{*}{$1993 / 94$} & 7,142 & 48.6 & 1,371 & 4.6 & $19.7(18.5,21.0)$ \\
$1994 / 95$ & 5,976 & 45.4 & 1,315 & 4.6 & $17.1(16.0,18.3)$ \\
$1995 / 96$ & 5,127 & 43.9 & 1,252 & 4.7 & $16.0(15.0,17.1)$ \\
$1996 / 97$ & 4,448 & 43.0 & 1,158 & 4.6 & $15.8(14.7,16.9)$ \\
$1997 / 98$ & 4,069 & 44.9 & 1,191 & 5.0 & $15.5(14.4,16.6)$ \\
$1998 / 99$ & 3,563 & 44.4 & 1,085 & 4.8 & $15.7(14.5,16.9)$ \\
\hline
\end{tabular}

Data Source: Ontario Health Insurance Plan (OHIP)

Table 1b: Numbers and odds ratios of Parkinsonian cases and controls seeing GPs* at least once in Ontario by fiscal year 1993/941998/99

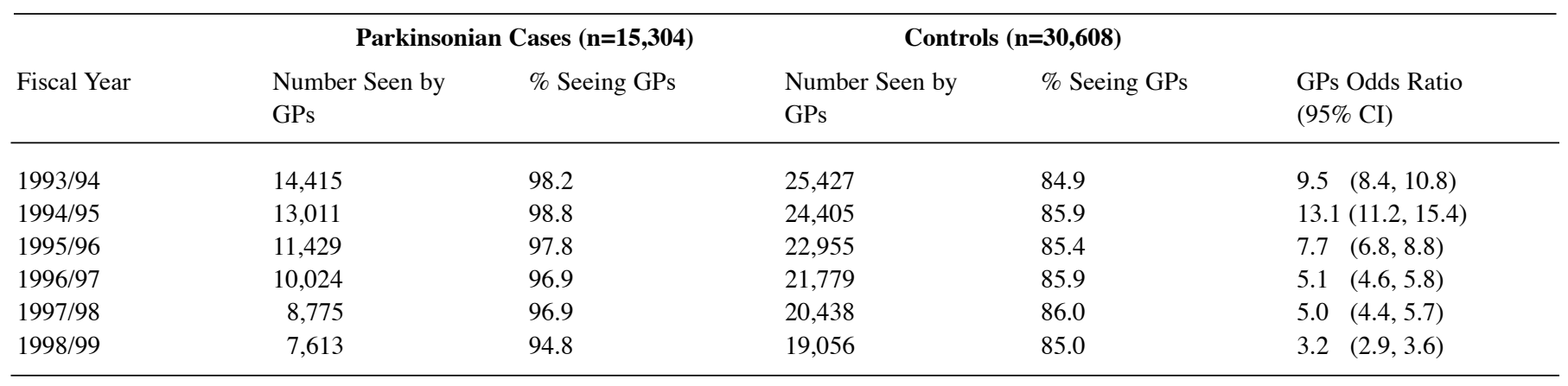

Data Source: Ontario Health Insurance Plan (OHIP)

*General Practitioner/Family Practitioner

Table 1c: Numbers and odds ratios of Parkinsonian cases and controls seeing internists at least once in Ontario by fiscal year 1993/941998/99

\begin{tabular}{llclll}
\hline & \multicolumn{2}{c}{ Parkinsonian Cases (n=15,304) } & \multicolumn{2}{c}{ Controls (n=30,608) } \\
Fiscal Year & $\begin{array}{l}\text { Number Seen by } \\
\text { Internists }\end{array}$ & \% Seeing Internists & $\begin{array}{l}\text { Number Seen by } \\
\text { Internists }\end{array}$ & \% Seeing Internists & $\begin{array}{l}\text { Internists Odds } \\
\text { Ratio (95\% CI) }\end{array}$ \\
\hline $1993 / 94$ & 7,600 & 51.7 & 13,150 & 43.9 & $1.4(1.3,1.4)$ \\
$1994 / 95$ & 6,711 & 50.9 & 12,815 & 45.1 & $1.3(1.2,1.3)$ \\
$1995 / 96$ & 5,845 & 50.0 & 11,989 & 44.6 & $1.2(1.2,1.3)$ \\
$1996 / 97$ & 5,168 & 50.0 & 11,505 & 45.4 & $1.2(1.1,1.3)$ \\
$1997 / 98$ & 4,577 & 50.5 & 11,167 & 47.0 & $1.2(1.1,1.2)$ \\
$1998 / 99$ & 3,929 & 48.9 & 10,458 & 46.7 & $1.1(1.0,1.1)$ \\
\hline
\end{tabular}

Data Source: Ontario Health Insurance Plan (OHIP) 
the Parkinsonian cohort had idiopathic PD or other types of Parkinsonism. We have, therefore, presented our results in terms of Parkinsonism rather than PD. Other conditions, including essential tremor, may be diagnosed as Parkinsonian in error and may have been included in the cohort. Furthermore, if patients were given anti-Parkinsonian treatment for reasons other than the diagnosis of PD such as Restless Leg Syndrome and Dystonia, they may have been included inappropriately.

The data used for these analyses were derived from three sources: prescription drug claims, physician service claims and the registry of all citizens for public administration. These data are collected routinely by these agencies for financial or administrative purposes; they are not collected primarily for research. Williams and Young $^{5}$ have summarized previous studies that examined the quality of health care administrative databases in Canada. Their overall conclusions were that demographic information is relatively complete and reliable and, although the coding systems have not kept pace with the changes in medical technology and clinical practice, billing claims for physician services are complete and relatively accurate. However, they flagged inter-individual variability in diagnostic coding accuracy by physicians. ${ }^{6}$ We addressed the latter concern by excluding PD claims rendered by some types of physicians and excluding cases where the PD diagnosis rested on physician claims made in only a single year.

To our knowledge, this is the first study to use linked databases to assess patterns of physician utilization in cases with Parkinsonism. This strategy has many strengths, including the selection of a large cohort of Parkinsonian patients, exact ageand sex-matching of the control group at a ratio of $1: 2$, and the capacity to prospectively follow the two groups over a six-year time period. The results of this study should provide information that is highly generalizable to the "real life" experience of the overall Parkinsonian population.

In conclusion, we have found that Parkinsonian cases saw neurologists less frequently than expected despite the universal health care system that is available in Ontario. In addition, there may be a potential age bias operating in access to neurological consultation. Parkinsonian cases had increased utilization of all study physician types, with higher OHIP costs as compared to controls. The overall proportion of physicians' costs related to neurological services, however, was quite small for Parkinsonian cases compared to other types of physicians. Since neurologists are the most highly-trained specialists to deal with Parkinsonism, it is possible that Parkinsonian patients are not receiving optimal care if they are not receiving neurological services. The large increase in physicians' costs associated with treating Parkinsonian patients emphasizes the impact of this condition on the health care system. This observational study was not designed to assess the outcome or quality of care that Parkinsonian patients received by the different types of physicians. Only a prospective, randomized controlled study with an extensive case-mix of the full clinical spectrum of Parkinsonism using patient outcome measures would be able to assess differences in quality of care based on physician utilization. If there is evidence to suggest that access to neurologic specialist care provides better outcomes for Parkinsonian cases, and if the associated costs are improved, then efforts must be made to re-evaluate and increase the availability of neurological services to this patient population. Further health services research in other health care systems is also important, to evaluate access to neurological care for Parkinsonian cases in other parts of the world and to validate our observations.

\section{ACKNOWLEDGEMENTS}

The authors thank Anne Bain, Linda Toews and Davida Glazer. This project was jointly funded by an unrestricted research grant from Parkinson Society Canada, National Parkinson Foundation (Miami) through a Center of Excellence Award to Dr. Guttman and the University of Toronto, and by the Institute for Clinical Evaluative Sciences.

\section{REFERENCES}

1. Miyasaki JM, Martin WRW, Suchowersky O, Weiner WJ, Lang AE. Practice parameter: initiation of treatment for Parkinson's disease: an evidence based review. Neurology 2002;58:11-17.

2. Guttman M, Slaughter PM, Theriault M-E, DeBoer DP, Naylor CD. Parkinsonism in Ontario: increased mortality compared to controls in a large cohort study. Neurology 2001;57:2278-2282.

3. Lang AE, Lozano AM. Parkinson's disease: first of two parts. N Engl J Med 1998;339(15):1044-1053.

4. Lang AE, Lozano AM. Parkinson's disease: second of two parts. N Engl J Med 1998;339:1130-1143.

5. Williams JI, Young W. A summary of studies on the quality of healthcare administrative databases in Canada. In: Goel V, Anderson GM, Fooks C, Iron K, Naylor CD, eds. Patterns of Health Care in Ontario: the ICES Practice Atlas 2nd edition. Ottawa: Canadian Medical Association, 1996:339-345.

6. Iron K. Technical Appendix. In: Naylor CD, Slaughter PM, eds. Cardiovascular Health and Services in Ontario: An ICES Atlas. Toronto: Institute for Clinical Evaluative Studies 1999:1-8. 